\title{
Aspergillus-related lung disease
}

\author{
Alia Al-Alawi $\mathrm{MB}^{1}$, C Frank Ryan $\mathrm{MB}^{2}$, Julia D Flint $\mathrm{MB}^{3}$, Nestor L Müller $\mathrm{MD}^{4}$
}

\begin{abstract}
A Al-Alawi, CF Ryan, JD Flint, NL Müller. Aspergillus-related lung disease. Can Respir J 2005;12(7):377-387.
\end{abstract}

Aspergillus is a ubiquitous dimorphic fungus that causes a variety of human diseases ranging in severity from trivial to life-threatening, depending on the host response. An intact host defence is important to prevent disease, but individuals with pre-existing structural lung disease, atopy, occupational exposure or impaired immunity are susceptible. Three distinctive patterns of aspergillus-related lung disease are recognized: saprophytic infestation of airways, cavities and necrotic tissue; allergic disease including extrinsic allergic alveolitis, asthma, allergic bronchopulmonary aspergillosis, bronchocentric granulomatosis and chronic eosinophilic pneumonia; and airway and tissue invasive disease - pseudomembranous tracheobronchitis, acute bronchopneumonia, angioinvasive aspergillosis, chronic necrotizing aspergillosis and invasive pleural disease. A broad knowledge of these clinical presentations and a high index of suspicion are required to ensure timely diagnosis and treatment of the potentially lethal manifestations of aspergillus-related pulmonary disease. In the present report, the clinical, radiographic and pathological aspects of the various aspergillus-related lung diseases are briefly reviewed.

\section{Une atteinte pulmonaire reliée à des aspergillus}

\begin{abstract}
L'aspergillus est un champignon dimorphe ubiquiste responsable de diverses maladies humaines qui peuvent être insignifiantes, mais aussi constituer un danger de mort, selon la réponse de l'hôte. La défense de l'hôte doit être intacte pour prévenir la maladie, mais les individus présentant déjà une atteinte pulmonaire structurelle, une atopie, une exposition professionnelle ou une atteinte immunitaire y sont prédisposés. Trois modèles distincts d'atteinte pulmonaire reliée à des aspergillus sont comptabilisés : l'infestation saprophytique des voies respiratoires, des cavernes et du tissu nécrotique, une atteinte allergique incluant la pneumopathie d'hypersensibilité, l'asthme, l'aspergillose bronchopulmonaire allergique, la granulomatose bronchocentrique et la pneumonie à éosinophiles chronique ainsi qu'une atteinte invasive des tissus et des voies respiratoires telle que la trachéobronchite pseudomembraneuse, la bronchopneumonie aiguë, l'aspergillose envahissant les vaisseaux sanguins, l'aspergillose nécrosante chronique et l'atteinte pleurale invasive. Des connaissances sur ces présentations cliniques et un fort indice de présomption sont nécessaires pour garantir le diagnostic et le traitement rapides des manifestations au potentiel mortel d'une atteinte pulmonaire reliée à des aspergillus. Dans le présent rapport, les aspects cliniques, radiographiques et pathologiques des diverses atteintes pulmonaires reliées à des aspergillus sont brièvement passés en revue.
\end{abstract}

Key Words: Aspergillosis; Aspergillus; Lung disease

$A$ spergillus is a ubiquitous dimorphic fungus that is present A worldwide (1). The fungus is commonly found on stored hay or grain, decaying vegetation, soil, water and various types of organic debris (2). Conidia are present virtually anywhere in the atmosphere and, although disease is uncommon, conidia are inhaled regularly. Many infections are probably derived from general atmospheric contamination, whereas others are related to the presence of organisms in specific sites, including contaminated marijuana cigarettes (3), and such hospital sources as pigeon excreta near ventilation systems and dust created during renovations. Outbreaks of invasive pulmonary aspergillosis in hospital wards have been described in association with hospital reconstruction and renovation (4). More than 300 Aspergillus species have been identified, of which only 19 cause human disease (5). The most common species is Aspergillus fumigatus, whereas Aspergillus niger, Aspergillus flawus and Aspergillus terreus are infrequently responsible for human infection (6).

The airborne conidia of A fumigatus have a diameter small enough $(2.5 \mu \mathrm{m}$ to $3.5 \mu \mathrm{m})$ to reach peripheral airways. If the conidia can overcome the immune defence mechanisms in the lung, they germinate and produce branched septate hyphae that invade the lung tissues (Figure 1). The virulence of A fumigatus

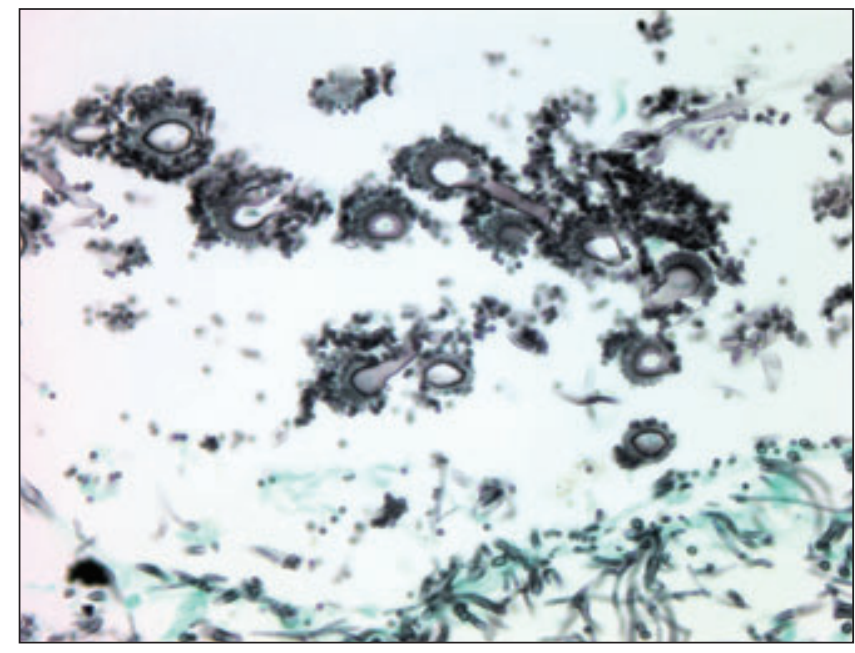

Figure 1) High-power photomicrograph (methenamine silver stain) showing aspergillus fruiting heads (conidiophores with sterigmata and conidia), which sometimes form in cavities that communicate with the atmosphere, thus exposing the organism to air. Branching fungal hyphae are also shown in the lower part of the image

${ }^{1}$ Division of Respiratory Medicine, Department of Medicine, Amiri Hospital, Safat, Kuwait; ${ }^{2}$ Division of Respiratory Medicine, Department of Medicine; ${ }^{3}$ Department of Pathology; ${ }^{4}$ Department of Radiology, University of British Columbia, Vancouver, British Columbia

Correspondence and reprints: Dr C Frank Ryan, University of British Columbia Respiratory Clinic, 2775 Heather Street, Vancouver,

British Columbia V5Z 3J5. Telephone 604-875-5710, fax 604-875-4695, e-mail fryan@interchange.ubc.ca 


\section{TABLE 1}

The spectrum of aspergillus-related lung disease

\begin{tabular}{l} 
Saprophytic infestation \\
Simple colonization \\
Aspergilloma \\
Invasion of necrotic tissue \\
Allergic disease \\
Extrinsic allergic alveolitis \\
Asthma \\
Allergic bronchopulmonary aspergillosis \\
Bronchocentric granulomatosis \\
Chronic eosinophilic pneumonia \\
Invasive aspergillosis \\
Pseudomembranous tracheobronchitis \\
Acute bronchopneumonia \\
Angioinvasive aspergillosis \\
Chronic necrotizing aspergillosis \\
Invasive pleural disease \\
\hline
\end{tabular}

is probably related to the production of fungal proteins that promote mycelial growth into the lung parenchyma, or to structural features of the conidia that confer resistance to the host's antifungal mechanisms (7). Aspergillus species produce a variety of toxic substances that are thought to be important in the pathogenesis of disease. These substances include endotoxins that have been shown to inhibit epithelial ciliary activity and a variety of proteases, including elastase, collagenase and trypsin, that can damage the epithelial tissue. The risk of developing disease depends on the interplay between the organism's virulence and the host's ability to resist infection. In addition to the host immune status, the other major factor that determines the resulting type of aspergillus reaction is the initial state of the lung parenchyma.

The first line of host defence against aspergillus is the respiratory tract epithelium, with the majority of A fumigatus conidia being extruded from the lung by the ciliary action of the mucous epithelium. In situations where such clearance appears to be deranged, as in bronchiectasis or in the cavities of chronic tuberculosis, the likelihood of fungal colonization and growth is greatly increased. Pulmonary macrophages and neutrophils constitute another important line of host defence (8). Large doses of corticosteroids inhibit the killing of conidia and hyphae by macrophages and inhibit migration of neutrophils around the fungus (9). Neutropenia is a major risk factor for invasive aspergillosis (10). In recent years, it has been shown that T-cell immunity and associated cytokines and/or chemokines have a role in the control of A fumigatus infection $(11,12)$.

In tissue, aspergillus typically grow as regular septate hyphae, with characteristic dichotomous branching at $45^{\circ}$ angles, which can usually be observed with hematoxylin and eosin stains, but are best observed with periodic acid-Schiff or Gomori's methenamine silver stains (Figure 1). Although aspergillus can infect virtually any organ, the lung is by far the most commonly affected. Within the lung, a spectrum of disease exists depending on the host's immune status, ranging from colonization of the airways in the immunocompetent patient to tissue invasion by the fungus in the severely immunocompromised patient. Although discrete syndromes have been described, there is some degree of overlap, perhaps reflecting the variability of immune response mounted by the host. Three distinctive patterns of aspergillus-related lung disease are recognized: saprophytic infestation of airways, cavities and necrotic tissue; allergic disease including extrinsic allergic alveolitis, asthma, allergic bronchopulmonary aspergillosis (ABPA), bronchocentric granulomatosis and chronic eosinophilic pneumonia; and airway and tissue invasive disease - pseudomembranous tracheobronchitis, acute bronchopneumonia, angioinvasive aspergillosis, chronic necrotizing aspergillosis and invasive pleural disease (Table 1).

\section{PULMONARY SYNDROMES RELATED TO ASPERGILLUS}

\section{Saprophytic infestation}

Simple colonization: Aspergillus can exist on body surfaces and in bronchi without eliciting a pathological response (13). It is particularly common in patients with underlying airway disease such as cystic fibrosis, asthma, chronic obstructive pulmonary disease (COPD) and bronchiectasis. Tissue invasion is not a feature of colonization, although pulmonary aspergillosis can develop if host defence is altered.

Aspergilloma: Saprophytic colonization of a parenchymal cavity by a fungus is termed a mycetoma or fungus ball, or in the case of Aspergillus species, an aspergilloma. A fungus ball consists of a grossly identifiable cluster of interwined hyphae matted together with a variable amount of mucus and cellular debris (7). It typically occurs in ectatic airways or parenchymal cavities. Conditions associated with aspergilloma formation include tuberculosis (14-24); sarcoidosis (18-28); histoplasmosis (18); lung abscess (14,20-24); bronchiectasis $(17,18,20,21)$; lung cancer $(17,23,28)$; bullae $(17,20,26,28)$; postradiation fibrosis $(21,22,24,28)$; pulmonary infarcts $(20,28)$; cavities associated with rheumatoid arthritis, ankylosing spondylitis and Wegner's granulomatosis $(20,21,24,28,29)$; cystic fibrosis $(30,31)$; allergic bronchopulmonary mycosis $(20,31)$; and HIV infection $(32,33)$.

Up to $50 \%$ of patients with pulmonary aspergilloma can be asymptomatic (22). Hemoptysis, occasionally massive and life threatening, is the most common clinical presentation, occurring in $74 \%$ of patients in one series (34). Other clinical features include cough and bronchorrhea, fever, weight loss and dyspnea. Plain chest radiographs classically show a mass within a cavity. Computed tomography (CT) characteristically shows an intracavitary mass with a surrounding air crescent most commonly in the upper lobes (Figure 2). The aspergilloma may move when the patient changes position (35). Thickening of the adjacent pleura is frequent. Positive sputum cultures for Aspergillus species can be seen in $58 \%$ of patients (23), with A niger being the most commonly identified type $(25,28)$. Sputum cultures, however, are of minor diagnostic value due to the ubiquitous presence of the fungus. Virtually all patients with an aspergilloma have precipitating antibodies to aspergillus antigens in their serum (36).

Treatment of aspergilloma remains problematic. Antifungal agents have been used with limited success. Nebulized antifungals have not been shown to reduce the size of the aspergilloma $(20,21)$. Systemic antifungals have led to no change or minimal reduction in the size of the fungus ball $(20,24,37)$. In fact, Hammerman et al (38) showed that intravenous administration of amphotericin B is no more effective than a pulmonary toilet regimen in the management of patients with aspergillomas. Intracavitary or endobronchial instillation of antifungal 
agents has also been attempted with variable outcomes $(20,23,26,39-45)$; these measures may stop life-threatening hemoptysis and improve clinical symptoms. Corticosteroid therapy may improve symptoms (20) but carries the risk of dissemination or enlargement of the fungus ball. Radiotherapy has been shown to control hemoptysis (46). Medical treatment is appropriate for symptomatic patients who are poor surgical candidates on account of their underlying disease.

Surgical resection of the affected lung is the definitive treatment for an aspergilloma. Unfortunately, surgery is associated with considerable morbidity (25\%) and mortality (8\% to $10 \%$ ) (22), and many patients are unsuitable because of limited pulmonary reserve. Postoperative complications include empyema, bronchopleural fistula, hemorrhage and infection including disseminated fungal infection. Some authors advocate prophylactic surgical treatment $(47,48)$, whereas others reserve it for symptomatic patients, mainly those with hemoptysis $(20,22,25)$. The unpredictable course of the illness in the absence of surgery confounds decisions about surgical intervention (49).

Invasion of necrotic tissue: Invasion of necrotic tissue is a rare form of aspergillus lung disease that manifests as colonization of nonviable lung parenchyma resulting from necrotizing pneumonia (lung gangrene) (50), pulmonary infarction (51) or a necrotic tumour (52). Unless the patient is immunocompromised, invasion of viable lung tissue does not occur.

\section{Allergic disease}

Extrinsic allergic alveolitis: Extrinsic allergic alveolitis, most likely the result of a hypersensitivity reaction to inhaled conidia, occurs after intense exposure to different Aspergillus species including A fumigatus, Aspergillus clavatus (53-55) and Aspergillus versicolor (56). It is usually seen in an occupational setting, especially among whiskey distilling and beer-brewing workers. Extrinsic allergic alveolitis caused by A clavatus is called malt-worker's lung $(53,54)$. Dog house disease is attributed to A versicolor (56). Cases of farmer's lung caused by A fumigatus have also been reported (57). Immunological evidence suggests that the disease is caused by either a type III or IV hypersensitivity response or a combination of both (58). Clinically, the illness may be insidious or acute in presentation depending on the intensity of exposure to the responsible antigen (59). Common presenting features include malaise, sweating, chills, myalgia, anorexia, dyspnea and a sense of tightness in the chest. Serum precipitins to aspergillus extracts are usually present (60). Spontaneous resolution of the acute lung changes may follow removal of the patient from further exposure. Corticosteroids are given to very ill patients and may lead to prompt resolution of the illness.

Allergic asthma: Allergic asthma is a type I hypersensitivity reaction that occurs in atopic individuals. It is more common between October and February when aspergillus spore counts are high (60). A skin test using aspergillus antigen produces an immediate reaction; however, this test lacks specificity. Bronchoprovocation with aspergillus antigen is usually positive. Precipitating antibodies are usually absent in such patients. Bronchodilators and inhaled corticosteroids are the treatment of choice (60).

ABPA: ABPA is a hypersensitivity reaction to A fumigatus that occurs in patients with asthma or cystic fibrosis. Its prevalence in asthmatic patients ranges from 3\% to $16 \%(61,62)$ and, in cystic fibrosis patients, from $2 \%$ to $8 \%(63-66)$. ABPA has also been reported in cystic fibrosis patients after undergoing

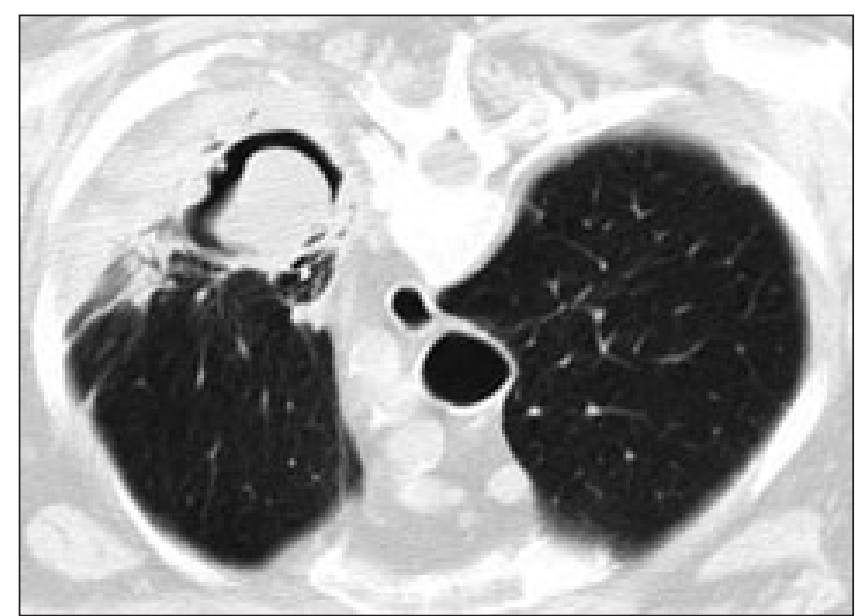

Figure 2) High-resolution computed tomography of the chest performed with the patient prone showing mycetoma within a left upper lobe cavity. Also shown is extensive pleural thickening. The patient was a 58-year-old man with chronic upper lobe scarring and bronchiectasis due to previous tuberculosis

lung transplantation (67). ABPA is characterized by inspissated mucous plugs containing aspergillus organisms and eosinophils resulting in chronic inflammation in the airway wall and bronchial ectasia. Patients develop recurrent episodes of wheezing, malaise, low-grade fever, cough, sputum production, hemoptysis, chest pain and pulmonary infiltrates. They may have a history of poorly controlled asthma, recurrent pneumonia and frequent antibiotic therapy. Regional lymphadenopathy associated with ABPA has been described $(68,69)$.

On plain radiographs, the characteristic pattern is fingerlike, homogeneous, branching opacities usually involving the segmental and more central subsegmental bronchi of the upper lobes (35). These findings are related to plugging of airways by hyphal masses with distal mucoid impaction (70). Mucous plugs may resolve quickly or last for a number of months. Resolution of the plugging may reveal residual, typically central, bronchiectasis, and bronchial wall thickening. These manifest as ring shadows or linear 'tram tracks' on the chest radiograph (35). The most common CT finding is central bronchiectasis with upper lobe predominance (Figure 3). Bronchiectasis affecting three or more lobes, centrilobular nodules and mucoid impaction are findings highly suggestive of ABPA (71). In approximately $30 \%$ of patients, the impacted mucus has high attenuation or demonstrates frank calcification on CT (70).

Bronchoscopy has been shown to have a role in the diagnosis of ABPA $(72,73)$, especially in patients with atypical manifestations and those who do not meet the standard diagnostic criteria (see below). Bronchoscopic examination in these two studies $(72,73)$ revealed evidence of mucous plugging. Histological examination of the mucous plugs showed that they consisted of so-called 'allergic mucin' containing fungal hyphae and eosinophils.

On histological examination, proximal airways containing mucous plugs are usually ectatic and inflamed. Eosinophils and plasma cells predominate and the airway epithelium is usually intact. Fungal invasion of the bronchial wall is almost never seen. Mucous plugs typically contain numerous eosinophils and Charcot-Leyden crystals, and have a laminated, somewhat 


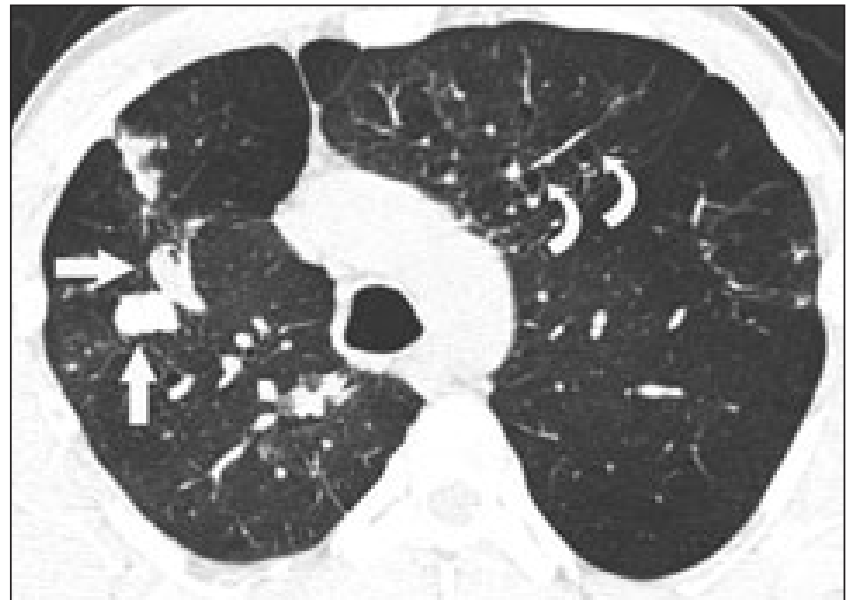

Figure 3) High-resolution computed tomography showing mucoid impaction (straight arrows) in the right upper lobe and varicose bronchiectasis (curved arrows) in the left upper lobe. The patient was a 54-year-old man with asthma and allergic bronchopulmonary aspergillosis

geometric appearance (Figure 4A). Fungal hyphae, often fragmented and sometimes swollen and degenerated in appearance, are difficult to identify on hematoxylin and eosin-stained sections, but usually can be readily seen with a silver stain (Figure 4B). Bronchocentric granulomatosis (see below) is another occasional histological abnormality seen in ABPA (7).

The diagnosis of ABPA is established using clinical, immunological and radiographic criteria (74). The major and minor diagnostic criteria are listed in Table 2. The presence of all major criteria confirms the diagnosis, and the presence of six criteria make the diagnosis of ABPA highly likely.

Five stages of the disease have been proposed:

- Stage I (acute stage) is associated with asthma, fever and productive cough with blood eosinophilia and pulmonary infiltrates. This stage is completely reversible with corticosteroids.

- Stage II (remission) is asymptomatic and associated with a normal chest radiograph and decreased serum immunoglobulin (Ig) E and eosinophilia.

- Stage III (recurrent exacerbation) is characterized by recurrence of the same findings of stage I in association with doubling of serum IgE concentrations.

- Stage IV (steroid-dependent) is characterized by symptomatic asthma requiring corticosteroid therapy for control.

- Stage V (fibrotic) is characterized by severe dyspnea, pulmonary fibrosis and a mixed obstructive/restrictive pattern on pulmonary function testing $(75,76)$.

Treatment of ABPA aims at relieving the acute exacerbations and preventing progressive lung damage. Early recognition and aggressive treatment of the early stages may halt progression. Corticosteroids are the cornerstone of treatment; however, most of the supportive data come from uncontrolled trials. Rosenberg et al (77) showed resolution of symptoms and active roentgenographic infiltrates when patients were administered prednisone $0.5 \mathrm{mg} / \mathrm{kg}$ body weight daily. Patients may need to

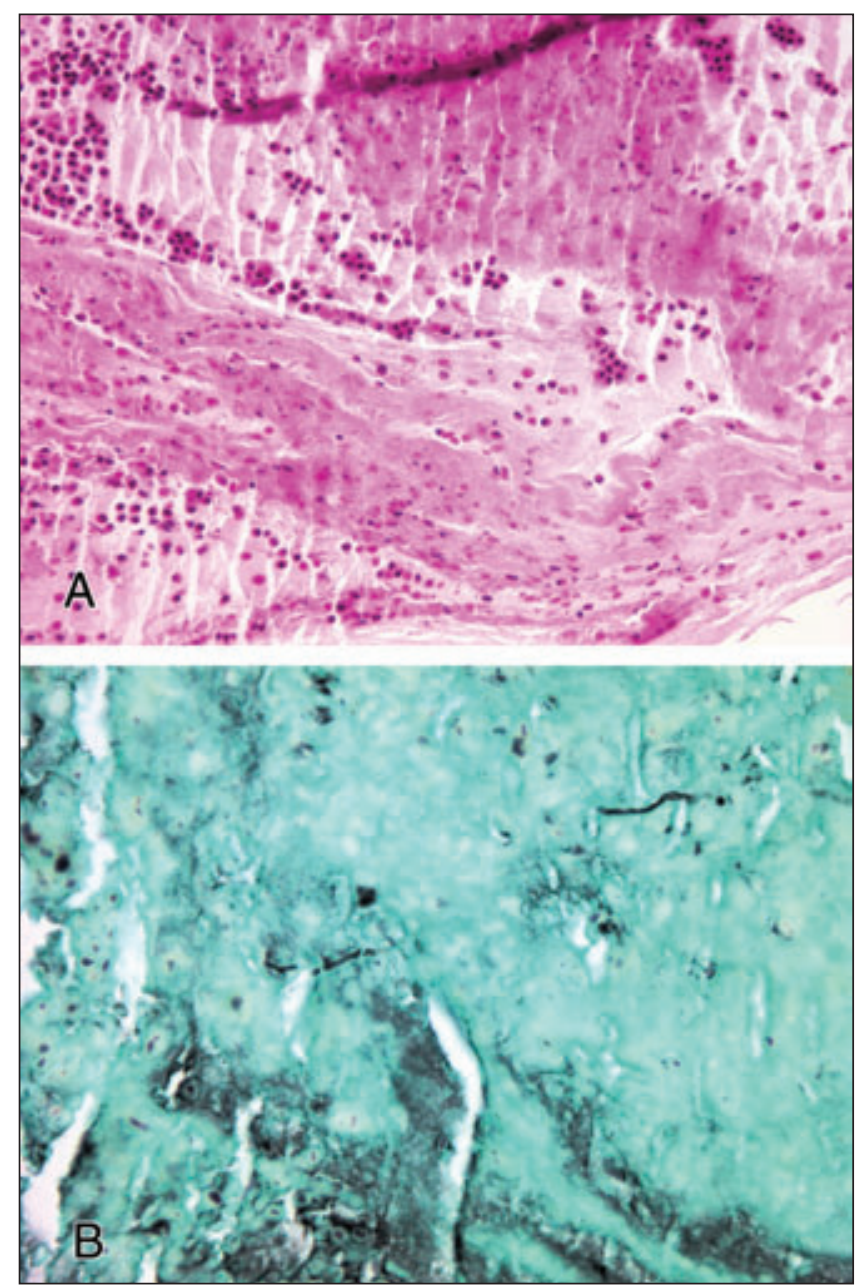

Figure 4) High-power photomicrographs of mucoid impaction in a patient with allergic bronchopulmonary aspergillosis. A Hematoxylin and eosin stain showing the laminated appearance of allergic mucin containing abundant eosinophils, eosinophilic debris and CharcotLeyden crystals. B Methenamine silver stain showing degenerating aspergillus hyphae within inspissated mucus

be maintained on low-dose corticosteroids after remission is achieved. In the same study, pulmonary infiltrates recurred in a few patients while they were receiving full maintenance alternate day prednisone. A $10 \mathrm{mg}$ daily dose of prednisone may be needed to prevent the recurrence of pulmonary infiltrates (78). Antifungal agents may have a role in the treatment of ABPA. A recent Cochrane review (79) concluded that itraconazole modifies the immunological activation associated with ABPA and improves clinical outcome, at least over the 16 weeks of treatment. Fifty patients with corticosteroid-dependent ABPA were randomly assigned to treatment with itraconazole $200 \mathrm{mg}$ twice daily or placebo for 16 weeks (80). The study showed a reduction of corticosteroid dose, a decrease in serum IgE level, an improvement in pulmonary function and resolution of pulmonary infiltrates in $46 \%$ of patients compared with $19 \%$ in the placebo group. Another randomized controlled trial (81) found that treatment of stable ABPA with itraconazole $400 \mathrm{mg}$ daily reduced airways eosinophilic inflammation, systemic immune activation and exacerbations. A few other nonrandomized studies (82-84) showed similar effects of 
TABLE 2

Allergic bronchopulmonary aspergillosis - diagnostic criteria

Major criteria
A history of asthma
Immediate skin test reactivity to aspergillus
Precipitating serum antibodies to Aspergillus fumigatus
Serum total IgE concentration greater than $1 \mu \mathrm{g} / \mathrm{mL}$
Peripheral blood eosinophilia $>500 / \mathrm{mm}^{3}$
Lung infiltrates
Central bronchiectasis
Elevated specific serum IgE and IgG to $A$ fumigatus
Minor criteria
A fumigatus in sputum (by repeated cultures or microscopic examination)
History of expectoration of brown plugs or flecks
Arthus reactivity (late skin reactivity) to aspergillus antigen

Ig Immunoglobulin

itraconazole in asthmatic and cystic fibrosis patients with ABPA. Itraconazole may therefore have a steroid sparing effect and play a role in steroid-dependent patients or those who refuse to take corticosteroids. Nebulized natamycin, however, did not confer any benefit when given to patients with steroid-dependent ABPA (85). Inhaled corticosteroids were shown to have no effect on the episodes of pulmonary eosinophilia; however, the control of asthma symptoms was improved by the addition of beclomethasone treatment to maintenance therapy (86). Imbeault and Cormier (87) demonstrated a steroid sparing effect of high-dose inhaled corticosteroids when used by two steroid-dependent ABPA patients. A study by Seaton et al (88) concluded that the use of inhaled corticosteroids is safe and effective in the management of ABPA when diagnosed before the occurence of hyphal colonization of the airways.

Obstructing bronchopulmonary aspergillosis is a form of noninvasive aspergillosis characterized by a massive overgrowth of Aspergillus species in the airways of patients with AIDS $(89,90)$. Although this condition shares some of the clinical and radiographic features of ABPA, the finding of tracheobronchial pseudomembranes on bronchoscopy suggests some overlap with pseudomembranous tracheobronchitis, a form of invasive aspergillosis discussed below.

Bronchocentric granulomatosis: Bronchocentric granulomatosis is a destructive granulomatous disease of the bronchi and bronchioles that occurs as a nonspecific reaction to airway injury (91). In approximately $50 \%$ of cases it occurs in the context of ABPA and is thought to be a hypersensitivity reaction to aspergillus (92). Peribronchiolar necrotizing granulomas cause destruction of airways and adjacent parenchyma (Figure 5). There is often associated mucoid impaction, eosinophilic pneumonia and fungal invasion of the surrounding parenchyma. The clinical features are those of ABPA. Occasionally, bronchocentric granulomatosis is the predominant histological pattern in chronic necrotizing aspergillosis, a form of invasive aspergillosis discussed below. Single or multiple pulmonary nodules are apparent radiographically (93). Excisional biopsy is required for the diagnosis but has not been shown to provide benefit. Some patients respond to corticosteroid therapy (92).

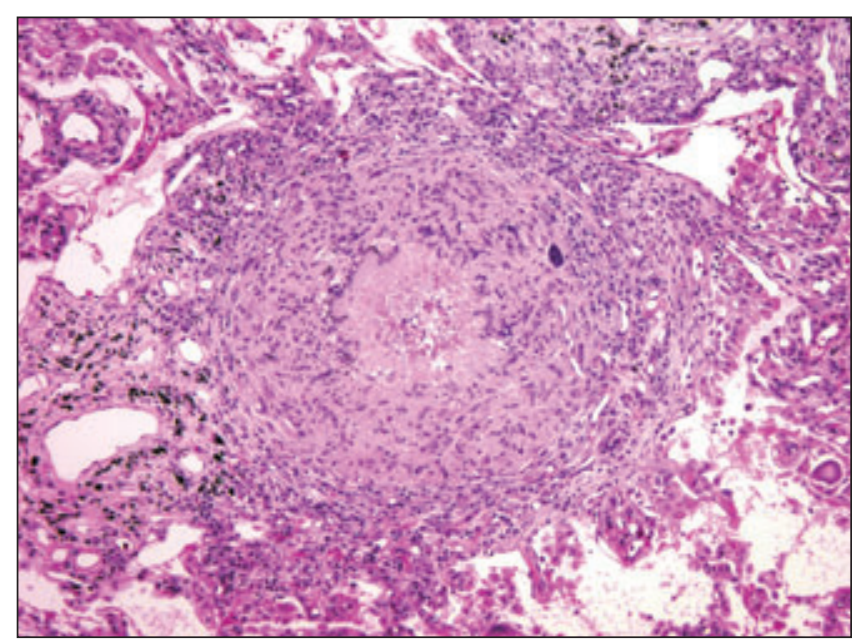

Figure 5) Medium-power photomicrograph showing necrotizing granulomata consisting of palisaded histiocytes and giant cells surrounding a necrotic bronchus containing fungal hyphae. The patient had bronchocentric granulomatosis due to aspergillus infection

Chronic eosinophilic pneumonia: Aspergillus has rarely been implicated as a cause of chronic eosinophilic pneumonia $(94,95)$. Patients present with the typical features of cough, dyspnea, fever and pulmonary infiltrates in a peripheral distribution. Histopathological features and response to corticosteroids are similar to those of other forms of this condition (94).

\section{Invasive aspergillosis}

Invasive aspergillosis, occurring in immunocompromised patients, is the most serious category of aspergillus-related lung disease because it can lead to disseminated disease and death within weeks. Predisposing conditions include bone marrow transplantation and hematological diseases such as leukemia or lymphoma (96), solid organ transplantation (97), solid tumours, chronic granulomatous disease (96), AIDS $(96,98,99)$ and patients treated with corticosteroids (100-102). Invasive aspergillosis occurs in several forms including tracheobronchial aspergillosis, acute bronchopneumonia, angioinvasive aspergillosis and chronic necrotizing (semi-invasive) aspergillosis.

Pseudomembranous tracheobronchitis: Aspergillus tracheobronchitis is an uncommon manifestation of acute aspergillus infection, occurring in approximately $5 \%$ of cases of invasive aspergillosis (103). Infection is confined to the larger airways, often with the formation of inflammatory pseudomembranes. Although unproved, it is suggested that aspergillus tracheobronchitis is more common in mildly to moderately immunocompromised patients, perhaps explaining its endobronchial location (104). There is a particular association with heart or heart-lung transplantation. In single-lung transplant recipients, infection may be confined to the transplanted side at the site of the bronchial anastomosis (105). In patients with COPD, infection has also been reported as a complication of the treatment of exacerbations with broad spectrum antibiotics and corticosteroids $(100,106)$. Histologically, there is focal or diffuse ulcerative tracheobronchitis with pseudomembranes, mucous plugs and fungal hyphae with superficial mucosal invasion and intense submucosal inflammation. Patients with aspergillus tracheobronchitis may be asymptomatic initially. 


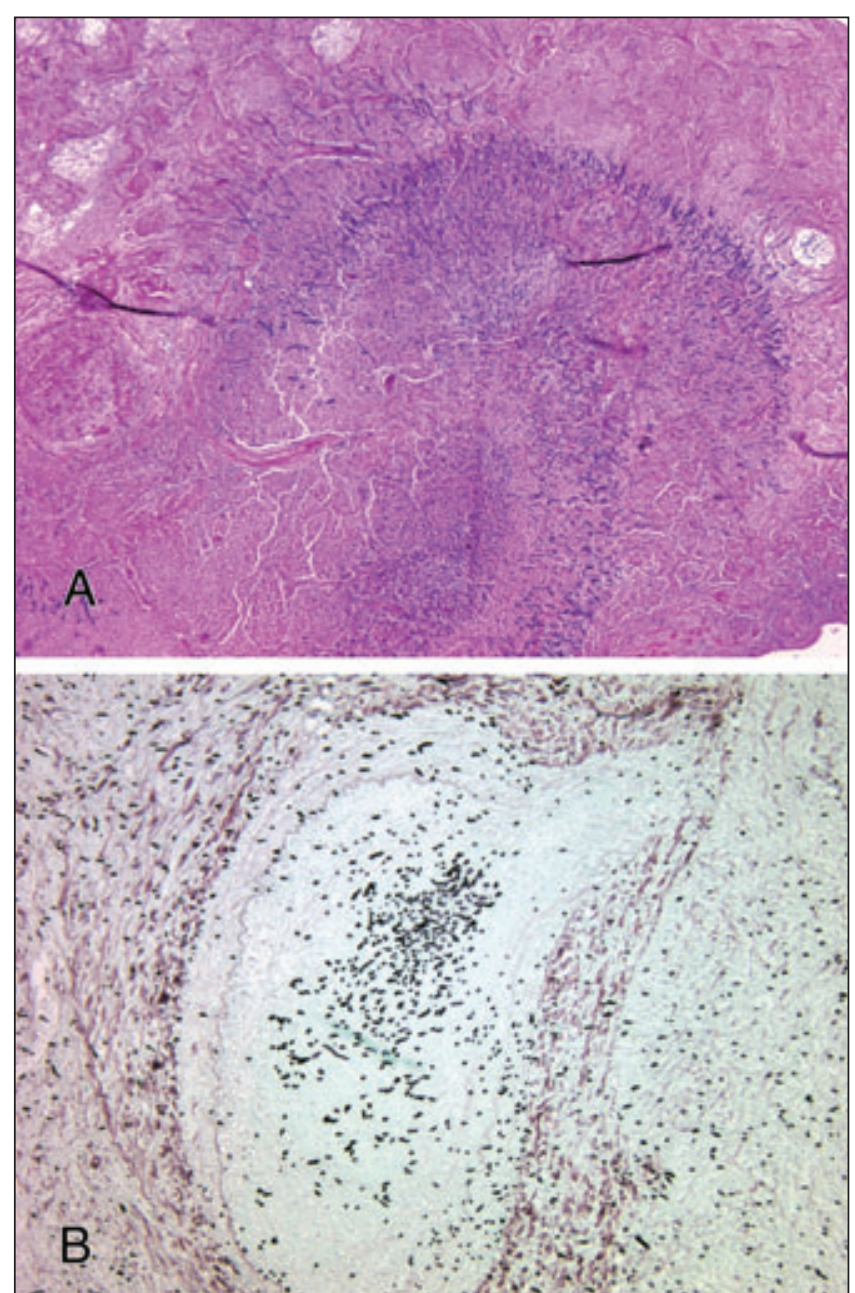

Figure 6) Medium-power photomicrographs showing invasive aspergillosis. A Hematoxylin and eosin stain showing tissue invasive aspergillosis with fungal hyphae growing radially in concentric layers, and an adjacent area of hemorrhagic pulmonary infarction (top left of image). B Methenamine silver stain showing angioinvasive aspergillosis with a blood vessel occluded by a mass of aspergillus organisms

The most common presenting complaints are cough, fever, dyspnea, chest pain and hemoptysis (103). Patients occasionally expectorate intraluminal mucous plugs or tracheobronchial casts. The chest radiograph may be unremarkable unless there is associated bronchopneumonia or atelectasis (35). High-resolution CT typically shows centrilobular nodules and a 'tree-in-bud' appearance (70), corresponding to dilated and impacted bronchioles imaged parallel or perpendicular to the imaging plane.

Acute bronchopneumonia (airway-invasive aspergillosis): Various histological patterns of acute aspergillus bronchopneumonia have been reported, including patchy ill-defined nodules centred around terminal bronchioles, sharply circumscribed small nodules with central cavitation, confluent airspace disease or larger nodules $(7,107)$. Occasionally, this pattern is seen in association with pseudomembranous tracheobronchitis, and vascular invasion can occur, suggesting that in terms of invasive behaviour, bronchopneumonia is intermediate between tracheobronchitis and angioinvasive disease. Patients typically

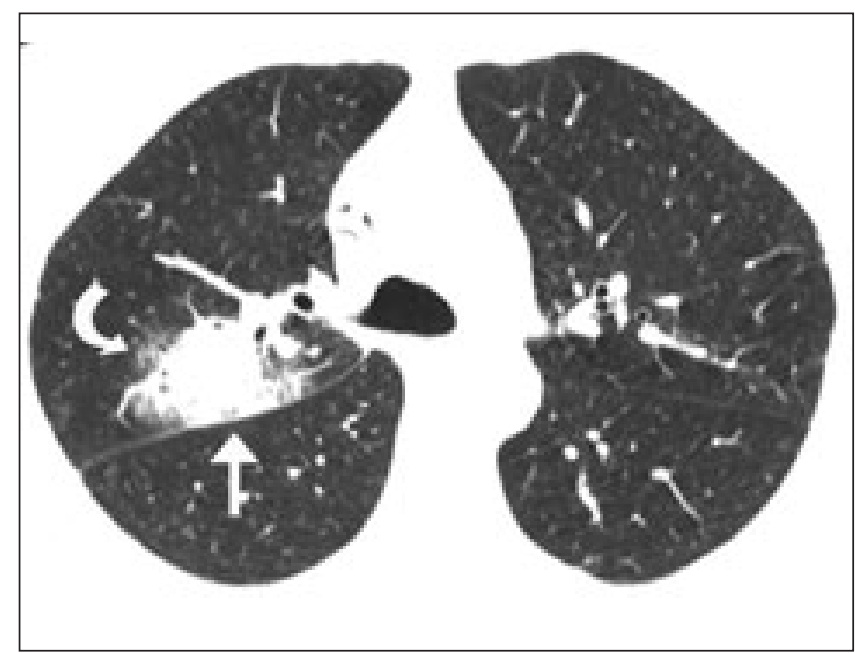

Figure 7) High-resolution computed tomography showing right upper lobe nodule (straight arrow) immediately anterior to the major fissure. Areas of ground glass attenuation (curved arrow) are seen adjacent to the nodule (computed tomography 'halo sign'). The patient was a 46-year-old man with acute myelogenous leukemia and angioinvasive aspergillosis

present with high fever progressing to respiratory failure if the disease is extensive. The chest radiograph shows patchy or confluent airspace disease or ill-defined nodules. The chest CT shows centrilobular nodules, a tree-in-bud pattern or consolidation in a peribronchial distribution $(89,108)$.

Angioinvasive aspergillosis: There are two histological variants of angioinvasive aspergillosis: a nodular variety (Figure 6A) and a disease caused by vascular damage (Figure 6B) producing pulmonary infarcts similar to those due to bland pulmonary emboli (7). Patients present with fever, dyspnea, nonproductive cough and pleuritic chest pain (1). The radiographic appearance reflects the previously mentioned pathological patterns. The initial abnormality consists of one or more subtle nodular opacities that may be overlooked. Typically, chest radiographs show rapid progression of these nodular opacities to form single or multiple areas of homogeneous consolidation (109). These lesions may show a characteristic 'halo sign' seen on CT (Figure 7) reflecting an area of alveolar hemorrhage surrounding a central nodule. The nodules with halos often progress to form air crescents that indicate necrotizing pneumonia (35). Other manifestations include wedge-shaped pleuralbased areas of consolidation reflecting the presence of subsegmental or segmental infarcts (35).

Although early recognition and therapy with antifungal agents appear to improve survival, early diagnosis is difficult. Definitive diagnosis requires biopsy from an involved organ yielding both histopathological evidence of acutely angled, branching, septated, nonpigmented hyphae measuring $2 \mu \mathrm{m}$ to $4 \mu \mathrm{m}$ in width and positive cultures yielding Aspergillus species (49); these criteria may not be attainable in very ill patients. The isolation of Aspergillus species from respiratory tract specimens in high-risk patients, especially leukemic or neutropenic patients, is a significant predictor of invasive disease $(110,111)$. Combined fungal stains and cultures have a sensitivity of $32 \%$ to $58 \%$ and a specificity of $92 \%$ to $99.7 \%$ $(112,113)$. Bronchoscopy yields a diagnosis in $22 \%$ to $30 \%$ of cases $(113,114)$. 
Several tests have been developed to detect aspergillus antigens, including galactomannan, using enzyme immunoassay $(115,116)$, immunoblot (117) and ELISA techniques (118). Maertens et al (119) found that detection of galactomannan antigenemia had $94 \%$ sensitivity and $99 \%$ specificity for the diagnosis of invasive aspergillosis in allogeneic stem cell transplant recipients. Positive serology preceded radiographic abnormalities by eight to nine days in over $80 \%$ of patients. Tests are also available to detect aspergillus antibodies $(120,121)$; however, these tests depend on a normal host immune response, which is absent in immunosupressed patients. A polymerase chain reaction test to detect DNA of Aspergillus species has been developed (122-124).

Successful therapy of invasive aspergillosis depends on early diagnosis and prompt initiation of treatment because delay is associated with a high fatality rate. Therefore, treatment should be started empirically, without awaiting definitive diagnosis in patients suspected of having invasive pulmonary aspergillosis. Amphotericin B is currently the drug of choice for the treatment of invasive aspergillosis $(125,126)$. It should be given at a dose of $1 \mathrm{mg} / \mathrm{kg} /$ day to $1.5 \mathrm{mg} / \mathrm{kg} /$ day (39). The overall response rate to amphotericin $\mathrm{B}$ is $37 \%$, with a range of $14 \%$ to $83 \%$ (127). Liposomal amphotericin B has been shown to be efficacious and safe, and it causes fewer nephrotoxic side effects $(128,129)$. It is reserved for patients who develop nephrotoxicity while receiving amphotericin B (49), and for those with marginal renal function or patients receiving other nephrotoxic medications (128-134). Response rates to itraconazole have been reported to be similar to those of amphotericin B $(24,135,136)$. In a large nonrandomized study (136), itraconazole resulted in a complete or partial response in $39 \%$ of patients, with $26 \%$ failing to respond. The absorption of itraconazole is unreliable in seriously ill patients with disturbed gastrointestinal function (137). Furthermore, itraconazole interacts with several medications. A logical therapeutic sequence would be to use intravenous amphotericin B first, stepping down to oral itraconazole for prolonged treatment (49). Voriconazole is a more recent triazole compound that has activity against aspergillus. In a multicentre randomized openlabel study (138), intravenous voriconazole had a greater likelihood of producing a complete or partial response, lower mortality and lower rates of several adverse reactions compared with intravenous amphotericin B. Although there are concerns about instances of breakthrough infections with yeasts and molds with reduced susceptibility to voriconazole (139), it is increasingly recommended as the initial therapy for invasive aspergillosis. The recommended regimen for voriconazole is $6 \mathrm{mg} / \mathrm{kg} 12$ hourly for two doses followed by a maintenance dose of $4 \mathrm{mg} / \mathrm{kg} 12$ hourly, stepping down to $200 \mathrm{mg}$ orally twice daily. More recent antifungal agents such as caspofungin and micafungin are currently under study and have shown efficacy in animal models and case reports in humans (140-142). Treatment of invasive aspergillosis should be prolonged beyond clinical resolution of the disease and correction of any potentially reversible underlying predisposing conditions.

Despite treatment with antifungal agents, mortality associated with invasive pulmonary aspergillosis continues to be high, ranging from $50 \%$ to $93 \%$ depending on the underlying disease (127). Surgical resection, in combination with antifungal agents, has been shown in some instances to be effective in the treatment of invasive aspergillosis $(143,144)$. Several adjuvant therapies are under study. These include interferon gamma

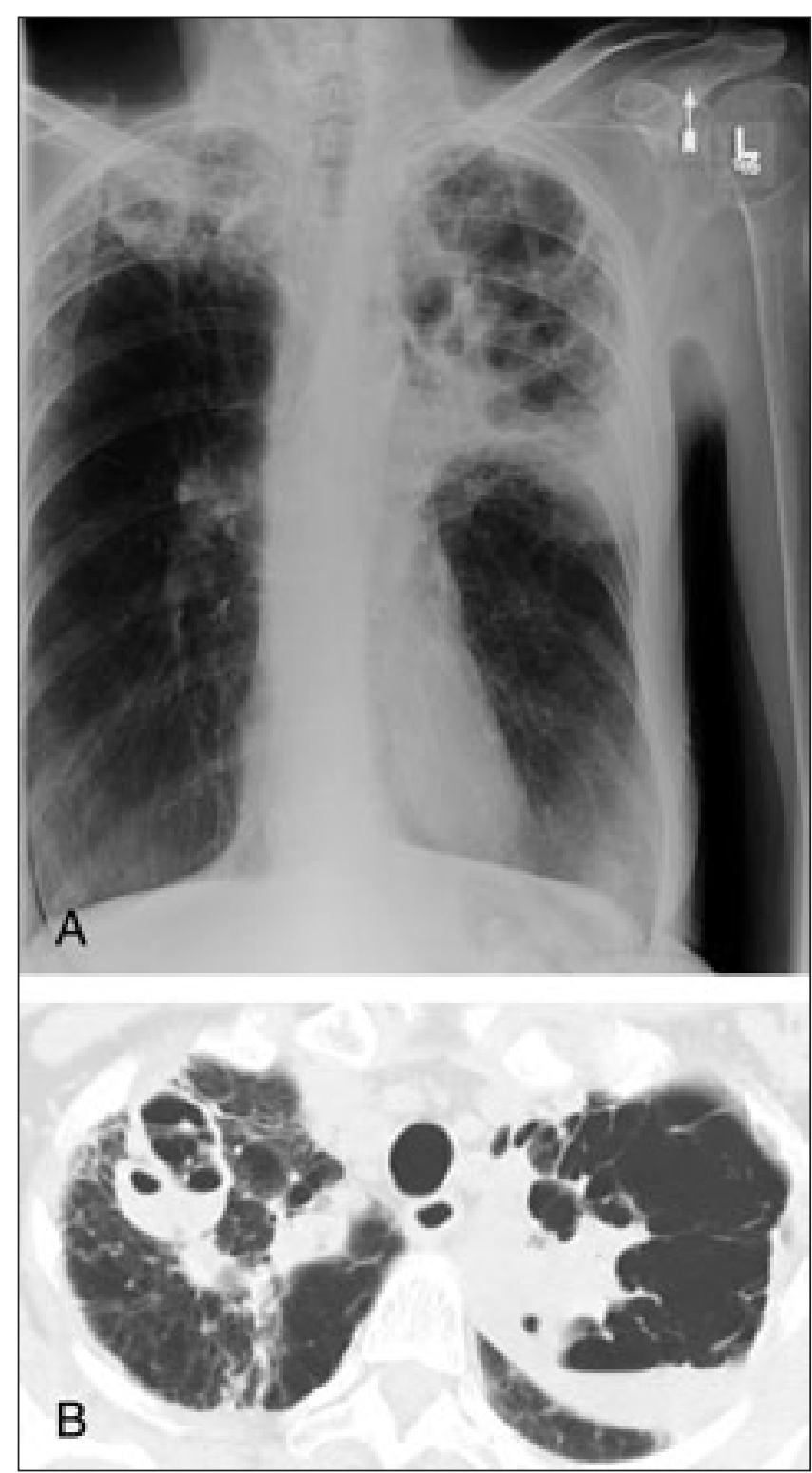

Figure 8) (A) Chest radiograph and (B) high-resolution computed tomography showing chronic necrotizing or semi-invasive aspergillosis. There is dense consolidation in the left upper lobe and focal consolidation in the right upper lobe, as well as an air-fluid level in a right upper lobe bulla. Computed tomography improves visualization of the underlying upper lobe emphysema. The patient was a 75-year-old woman with chronic obstructive pulmonary disease. The radiographic findings progressed over six months. Aspergillus species was the only pathogen grown on several cultures

(145), granulocyte colony-stimulating factor (CSF) (146), macrophage-CSF (147) and granulocyte transfusions (148). Improved survival has not been reported with any of these modalities. Some preventive strategies to reduce the risk of contracting invasive aspergillosis in high-risk patients include reduction of exposure to aspergillus by the use of high-efficiency particulate air filters (149), prophylactic nebulized amphotericin B (150), systemic amphotericin B (151) or systemic azoles $(152,153)$, and administration of granulocyte-CSF to shorten the period of neutropenia (149). 
Chronic necrotizing aspergillosis: Semi-invasive aspergillosis, also known as chronic necrotizing aspergillosis, has recently been recognized as a different type of infection that does not fit into traditional categories. It runs a more indolent course, occurring in patients with mildly impaired immunity. Among the conditions associated with the development of semi-invasive aspergillosis are COPD, diabetes mellitus, poor nutrition, alcoholism, connective tissue disease and treatment with corticosteroids $(154,155)$. The most common presenting complaints are fever, cough, sputum production (154) and weight loss (155). Symptoms may relate to the underlying lung disease, but the fungus is thought to be responsible for the slowly progressive tissue destruction. The duration of symptoms before the institution of therapy ranges from one month to greater than two years (154). The radiographic findings consist of upper lobe consolidation, multiple nodules (156) and cavitary disease (154) (Figure 8). Pathological patterns include necrotizing granulomatous pneumonia, granulomatous bronchiectatic cavities and bronchocentric granulomatosis. Chronic necrotizing aspergillosis is occasionally confined to the airways without evidence of extension into the lung parenchyma (89). Antifungals are the mainstay of treatment $(154,155)$. Itraconazole, with a response rate of $90 \%$, is the most effective

\section{REFERENCES}

1. Fraser RS, Müller NL, Colman N, Pare PD, eds. Diagnosis of Diseases of the Chest, 4th edn. Philadelphia: Saunders, 1999:919-47.

2. Schwarz J. Aspergillosis. In: Sommers SC, ed. Pulmonary Pathology Decennial 1965-75. New York: Appleton-Century-Crofts, 1975:293-320.

3. Kagen SL. Aspergillus: An inhalable contaminant of marihuana. N Engl J Med 1981;304:483-4.

4. Arnow PM, Anderson RL, Mainous PD, Smith EO. Pulmonary aspergillosis during hospital renovation. Am Rev Respir Dis 1978;118:49-53.

5. Bardana EJ Jr. The clinical spectrum of aspergillosis - Part 1: Epidemiology, pathogenicity, infection in animals and immunology of Aspergillus. Crit Rev Clin Lab Sci 1981;13:21-83.

6. Denning DW. Aspergillosis. In: Mandell GL, Bennett JE, Dolin R, eds. Principles and Practice of Infectious Diseases, 5th edn. Philadelphia: WB Saunders, 2000:2674-82.

7. Fraser RS. Pulmonary aspergillosis: Pathologic and pathogenetic features. Pathol Annu 1993;28:231-77.

8. Morgenstern DE, Gifford MA, Li LL, Doerschuk CM, Dinauer MC. Absence of respiratory burst in X-linked chronic granulomatous disease mice leads to abnormalities in both host defence and inflammatory response to Aspergillus fumigatus. J Exp Med 1997;185:207-18.

9. Palmer LB, Greenberg HE, Schiff MJ. Corticosteroid treatment as a risk factor for invasive aspergillosis in patients with lung disease. Thorax 1991;46:15-20.

10. Gerson SL, Talbot GH, Hurwitz S, Strom BL, Lusk EJ, Cassileth PA. Prolonged granulocytopenia: The major risk factor for invasive aspergillosis in patients with acute leukemia. Ann Intern Med 1984;100:345-51

11. Wald A, Leisenring W, van Burik JA, Bowden RA. Epidemiology of Aspergillus infections in a large cohort of patients undergoing bone marrow transplantation. J Infect Dis 1997;175:1459-66.

12. Hebart H, Bollinger C, Fisch P, et al. Analysis of T-cell responses to Aspergillus fumigatus antigens in healthy individuals and patients with hematological malignancies. Blood 2002;100:4521-8.

13. Kahanpää A. Bronchopulmonary occurrence of fungi in adults especially according to cultivation material. Acta Pathol Microbiol Scand [B] Microbiol Immunol 1972;227:1-147.

14. Babatasi G, Massetti M, Chapelier A, et al. Surgical treatment of pulmonary aspergilloma: Current outcome. J Thorac Cardiovasc Surg 2000;119:906-12.

15. Kawamura S, Maesaki S, Tomono K, Tashiro T, Kohno S. Clinical evaluation of 61 patients with pulmonary aspergilloma. Intern Med 2000;39:191-2. therapy currently available (155). Intravenous and intracavitary amphotericin B and 5-flourouracil have also been used, with the highest response rates obtained with intracavitary amphotericin B (155).

Invasive pleural disease: The pleural space occasionally becomes infected with aspergillus. Most commonly this occurs in patients who have undergone artificial pneumothorax therapy for pulmonary tuberculosis (157). Presumably, the organism gains entry to the pleural space from colonization or infection of adjacent damaged lung parenchyma. Pleural aspergillosis can also complicate lobectomy or pneumonectomy for tuberculosis or lung cancer, and is usually accompanied by a bronchopleural fistula (158). Pleural involvement either as direct invasion of the pleural cavity or as pleural fibrosis has been reported as a complication of chronic cavitary and fibrosing pulmonary aspergillosis (159). Although rare, infection of the pleural space may occur in the setting of disseminated aspergillosis (160). Clinical features are those of an acute or chronic empyema. Radiographs typically show pleural thickening and an air-fluid level. Treatment consists of extensive surgical debridement, systemic antifungal therapy and, occasionally, intrapleural instillation of antifungal agents together with prolonged drainage.

16. Regnard JF, Icard P, Nicolosi M, et al. Aspergilloma: A series of 89 surgical cases. Ann Thorac Surg 2000;69:898-903.

17. Kaestel M, Meyer W, Mittelmeier HO, Gebhardt C. Pulmonary aspergilloma - Clinical findings and surgical treatment. Thorac Cardiovasc Surg 1999;47:340-5

18. Rumbak M, Kohler G, Eastrige C, Winer-Muram H, Gavant M Topical treatment of life threatening haemoptysis from aspergilloma. Thorax 1996;51:253-5.

19. Tomlinson JR, Sahn SA. Aspergilloma in sarcoid and tuberculosis. Chest 1987;92:505-8.

20. Jewkes J, Kay PH, Paneth M, Citron KM. Pulmonary aspergilloma: Analysis and prognosis in relation to haemoptysis and survey of treatment. Thorax 1983;38:572-8.

21. Rafferty P, Biggs BA, Crompton GK, Grant IW. What happens to patients with pulmonary aspergilloma? Analysis of 23 cases. Thorax 1983;38:579-83.

22. Massard G, Roeslin N, Wihlm JM, Dumont P, Witz JP, Morand G. Pleuropulmonary aspergilloma: Clinical spectrum and results of surgical treatment. Ann Thorac Surg 1992;54:1159-64.

23. Yamada H, Kohno S, Koga H, Maesaki S, Kaku M. Topical treatment of pulmonary aspergilloma by antifungals. Relationship between duration of the disease and efficacy of therapy. Chest 1993; 103:1421-5.

24. Dupont B. Itraconazole therapy in aspergillosis: Study in 49 patients. J Am Acad Dermatol 1990;23:607-14.

25. Israel HL, Lenchner GS, Atkinson GW. Sarcoidosis and aspergilloma. The role of surgery. Chest 1982;82:430-2.

26. Shapiro MJ, Albelda SM, Mayock RL, McLean GK. Severe hemoptysis associated with pulmonary aspergilloma. Chest 1988;94:1225-31.

27. Kaplan J, Johns CJ. Mycetomas in pulmonary sarcoidosis: Non-surgical management. Johns Hopkins Med J 1979;145:157-61.

28. Daly RC, Pairolero PC, Piehler JM, Trastek VF, Payne WS, Bernatz PE. Pulmonary aspergilloma. Results of surgical treatment. J Thorac Cardiovasc Surg 1986;92:981-8.

29. Le Thi Huong D, Wechsler B, Chamuzeau JP, Bisson A, Godeau P. Pulmonary aspergilloma complicating Wegner's granulomatosis. Scand J Rheumatol 1995;24:260.

30. Maguire CP, Hayes JP, Hayes M, Masterson J, Fitzgerald MX. Three cases of pulmonary aspergilloma in adult patients with cystic fibrosis. Thorax 1995;50:805-6.

31. Denning DW. Commentary: Unusual manifestations of aspergillosis. Thorax 1995;50:812-3.

32. Addrizzo-Harris DJ, Harkin TJ, McGuinness G, Naidich DP, Rom WN. Pulmonary aspergilloma and AIDS. A comparison of HIV infected and HIV-negative individuals. Chest 1997;111:612-8. 
33. Schouwink JH, Weigel HM, Blaauwgeers JL, Schreurs AJ. Aspergilloma formation in a pneumatocele associated with Pneumocystis carinii pneumonia. AIDS 1997;11:135-7.

34. Glimp RA, Bayer AS. Pulmonary aspergilloma. Diagnostic and therapeutic considerations. Arch Intern Med 1983;143:303-8.

35. Logan PM, Müller NL. High-resolution computed tomography and pathologic findings in pulmonary aspergillosis: A pictorial essay. Can Assoc Radiol J 1996;47:444-52.

36. Longbottom JL, Pepys J, Clive FT. Diagnostic precipitin test in Aspergillus pulmonary mycetoma. Lancet 1964;13:588-9.

37. De Beule K, De Doncker P, Cauwenbergh G, et al. The treatment of aspergillosis and aspergilloma with itraconazole, clinical results of an open international study (1982-1987). Mycoses 1988;31:476-85.

38. Hammerman KJ, Sarosi GA, Tosh FE. Amphotericin B in the treatment of saprophytic forms of pulmonary aspergillosis. Am Rev Respir Dis 1974;109:57-62.

39. Itoh $\mathrm{T}$, Yamada $\mathrm{H}$, Yamaguchi $\mathrm{A}$, et al. Percutaneous intracavitary antifungals for a patient with pulmonary aspergilloma; with a special reference to in vivo efficacies and in vitro susceptibility results. Intern Med 1995;34:85-8.

40. Tsushima K, Fujimoto K, Kubo K, Sekiguchi M. Successful treatment of fungus ball in patients with allergic bronchopulmonary aspergillosis: Continuous percutaneous instillation of antifungal agents into the cavity. Intern Med 1996;35:736-41.

41. Giron J, Poey C, Fajadet P, et al. CT-guided percutaneous treatment of inoperable pulmonary aspergillomas: A study of 40 cases. Eur J Radiol 1998;28:235-42.

42. Munk PL, Vellet AD, Rankin RN, Müller NL, Ahmad D. Intracavitary aspergilloma: Transthoracic percutaneous injection of amphotericin gelatin solution. Radiology 1993;188:821-3.

43. Klein JS, Fang K, Chang MC. Percutaneous transcatheter treatment of an intracavitary aspergilloma. Cardiovasc Intervent Radiol 1993; 16:321-4.

44. Jackson M, Flower CD, Shneerson JM. Treatment of symptomatic pulmonary aspergillomas with intracavitary instillation of amphotericin B through an indwelling catheter. Thorax 1993;48:928-30.

45. Guleria R, Gupta D, Jindal SK. Treatment of pulmonary aspergilloma by endoscopic intracavitary instillation of ketoconazole. Chest 1993;103:1301-2.

46. Shneerson JM, Emerson PA, Phillips RH. Radiotherapy for massive haemoptysis from aspergilloma. Thorax 1980;35:953-4.

47. Soltanzadeh H, Wychulis AR, Sadr F, Bolanowski P, Neville WE. Surgical treatment of pulmonary aspergilloma. Ann Surg 1977;186:13-6.

48. Karas A, Hankins JR, Attar S, Miller J, McLaughlin JS. Pulmonary aspergillosis: An analysis of 41 patients. Ann Thorac Surg 1976;22:1-7.

49. Stevens DA, Kan VL, Judson MA, et al. Practice guidelines for diseases caused by aspergillus. Infectious Diseases Society of America. Clin Infect Dis 2000;30:696-709.

50. Buchanan DR, Lamb D. Saprophytic invasion of infarcted pulmonary tissue by Aspergillus species. Thorax 1982;37:693-8.

51. Przyjemski C, Mattii R. The formation of pulmonary mycetomata. Cancer 1980;46:1701-4

52. McGregor DH, Papasian CJ, Pierce PD. Aspergilloma within cavitating pulmonary adenocarcinoma. Am J Clin Pathol 1989;91:100-3.

53. Riddle HF, Channell S, Blyth W, et al. Allergic alveolitis in a maltworker. Thorax 1968;23:271-80.

54. Channell S, Blyth W, Lloyd M, et al. Allergic alveolitis in maltworkers: A clinical, mycological and immunological study. Q J Med 1969;38:351-76.

55. Reynolds HY. Hypersensitivity pneumonitis. Clin Chest Med 1982;3:503-19.

56. Rhudy J, Burrell R, Morgan W. Yet another cause of allergic alveolitis. Scand J Respir Dis 1971;52:177-80.

57. Smyth JT, Adkins GE, Margaret L, Moore B, McWhite E. Farmer's lung in Devon. Thorax 1975;30:197-203.

58. Richerson HB. Hypersensitivity pneumonitis - Pathology and pathogenesis. Clin Rev Allergy 1983;1:469-86.

59. Bardana EJ Jr. The clinical spectrum of aspergillosis - Part 2: Classification and description of saprophytic, allergic, and invasive variants of human disease. Crit Rev Clin Lab Sci 1980;13:85-159.

60. Sharma OP, Chwogule R. Many faces of pulmonary aspergillosis. Eur Respir J 1998;12:705-15

61. Al-Mobeireek AF, El-Rab MOGAD, Al-Hedaithy SS, Alasali K, Al-Majed S, Joharjy I. Allergic bronchopulmonary mycosis in patients with asthma: Period prevalence at a university hospital in Saudi Arabia. Respir Med 2001;95:341-7.

62. Kumar R, Gaur SN. Prevalence of allergic bronchopulmonary aspergillosis in patients with bronchial asthma. Asian Pac J Allergy Immunol 2000;18:181-5.

63. Taccetti G, Procopio E, Marianelli L, Campana S. Allergic bronchopulmonary aspergillosis in Italian cystic fibrosis patients: Prevalence and percentage of positive tests in the employed diagnostic criteria. Eur J Epidemiol 2000;16:837-42.

64. Mastella G, Rainisio M, Harms HK, et al. Allergic bronchopulmonary aspergillosis in cystic fibrosis. A European epidemiology study. Epidemiologic Registry of Cystic Fibrosis. Eur Respir J 2000;16:464-71.

65. Geller DE, Kaplowitz H, Light MJ, Colin AA. Allergic bronchopulmonary aspergillosis in cystic fibrosis: Reported prevalence, regional distribution, and patient characteristics. Scientific Advisory Group, Investigators, and Coordinators of the Epidemiology Study of Cystic Fibrosis. Chest 1999;116:639-46.

66. Mroueh S, Spock A. Allergic bronchopulmonary aspergillosis in patients with cystic fibrosis. Chest 1994;105:32-6.

67. Egan JJ, Yonan N, Carroll KB, Deiraniya AK, Webb AK, Woodcock AA. Allergic bronchopulmonary aspergillosis in lung allograft recipients. Eur Respir J 1996;9:169-71.

68. Shah A, Agarwal AK, Chugh IM. Hilar adenopathy in allergic bronchopulmonary aspergillosis. Ann Allerg Asthma Immunol 1999;82:504-6. (Erratum in 1999;82:542).

69. Hachiya T, Koyama S, Kubo K, Sekiguchi M, Honda T. Elevated serum CA19-9 level and regional lymphadenopathy in a young man with allergic bronchopulmonary aspergillosis. Intern Med 1998;37:91-3

70. Franquet T, Muller NL, Gimenez A, Guembe P, de La Torre J, Bague S. Spectrum of pulmonary aspergillosis: Histologic, clinical, and radiologic findings. Radiographics 2001;21:825-37.

71. Ward S, Heyneman L, Lee MJ, Leung AN, Hansell DM, Muller NL. Accuracy of CT in the diagnosis of allergic bronchopulmonary aspergillosis in asthmatic patients. Am J Roentgenol 1999;173:937-42.

72. Tamura A, Hebisawa A, Kurashima A, et al. The use of bronchofibroscopy for diagnosis of allergic bronchopulmonary aspergillosis. Intern Med 1997;36:865-9.

73. Aubry MC, Fraser R. The role of bronchial biopsy and washing in the diagnosis of allergic bronchopulmonary aspergillosis. Mod Pathol 1998;11:607-11.

74. Rosenberg M, Patterson R, Mintzer R, Cooper BJ, Roberts M, Harris KE. Clinical and immunologic criteria for the diagnosis of allergic bronchopulmonary aspergillosis. Ann Intern Med 1977;86:405-14.

75. Mendelson EB, Fisher MR, Mintzer RA. Roentographic and clinical staging of allergic bronchopulmonary aspergillosis. Chest 1985;87:334-9.

76. Patterson R, Greenberger PA, Radin RC, Roberts M. Allergic bronchopulmonary aspergillosis: Staging as an aid to management. Ann Intern Med 1982;96:286-91.

77. Rosenberg M, Patterson R, Roberts M, Wang J. The assessment of immunologic and clinical changes occurring during corticosteroid therapy for allergic bronchopulmonary aspergillosis. Am J Med 1978;64:599-606.

78. Middleton WG, Paterson IC, Grant IW, Douglas AC. Asthmatic pulmonary eosinophilia: A review of 65 cases. Br J Dis Chest 1977;71:115-22.

79. Wark PAB, Gibson PG, Wilson AJ. Azoles for allergic bronchopulmonary aspergillosis associated with asthma. Cochrane Database Syst Rev 2005:CD001108.

80. Stevens DA, Schwartz HJ, Moskovitz BL, et al. A randomized trial of itraconazole in allergic bronchopulmonary aspergillosis. N Engl J Med 2000;342:756-62.

81. Wark PA, Hensley MJ, Saltos N, et al. Anti-inflammatory effect of itraconazole in stable allergic bronchopulmonary aspergillosis: A randomized controlled trial. J Allergy Clin Immunol 2003;111:952-7.

82. Salez F, Brichet A, Desurmont S, Grosbois JM, Wallaert B, Tonnel AB. Effects of itraconazole therapy in allergic bronchopulmonary aspergillosis. Chest 1999;116:1665-8.

83. Germaud P, Tuchais E. Allergic bronchopulmonary aspergillosis treated with itraconazole. Chest 1995;107:883.

84. Nepomuceno IB, Esrig S, Moss RB. Allergic bronchopulmonary aspergillosis in cystic fibrosis: Role of atopy and response to itraconazole. Chest 1999;115:364-70. 
85. Currie DC, Lueck C, Milburn HJ, et al. Controlled trial of natamycin in the treatment of allergic bronchopulmonary aspergillosis. Thorax 1990;45:447-50.

86. Report to the Research Committee of the British Thoracic Association. Inhaled beclomethasone dipropionate in allergic bronchopulmonary aspergillosis. Br J Dis Chest 1979;73:349-56.

87. Imbeault B, Cormier Y. Usefulness of inhaled high-dose corticosteroids in allergic bronchopulmonary aspergillosis. Chest 1993;103:1614-7.

88. Seaton A, Seaton RA, Wightman AJ. Management of allergic bronchopulmonary aspergillosis without maintenance oral corticosteroids: A fifteen-year follow-up. QJM 1994;87:529-37.

89. Franquet T, Muller NL, Oikonomou A, Flint JD. Aspergillus infection of the airways: Computed tomography and pathologic findings. J Comput Assist Tomogr 2004;28:10-6.

90. Miller WT Jr, Sais GJ, Frank I, Gefter WB, Aronchick JM, Miller WT. Pulmonary aspergillosis in patients with AIDS. Clinical and radiographic correlations. Chest 1994;105:37-44.

91. Liebow AA. The J Burns Amberson lecture - pulmonary angiitis and granulomatosis. Am Rev Respir Dis 1973;108:1-18.

92. Katzenstein AL, Liebow AA, Friedman PJ. Bronchocentric granulomatosis, mucoid impaction, and hypersensitivity reactions to fungi. Am Rev Respir Dis 1975;111:497-537.

93. Robinson RG, Wehunt WD, Tsou E, Koss MN, Hochholzer L. Bronchocentric granulomatosis: Roentgenographic manifestations. Am Rev Respir Dis 1982;125:751-6.

94. Jederlinic PJ, Sicilian L, Gaensler EA. Chronic eosinophilic pneumonia: A report of 19 cases and a review of the literature. Medicine (Baltimore) 1988;67:154-62.

95. Warnock ML, Fennessy J, Rippon J. Chronic eosinophilic pneumonia, a manifestation of allergic aspergillosis. Am J Clin Pathol 1974;62:73-81.

96. Patterson TF, Kirkpatrick WR, White M, et al. Invasive aspergillosis. Disease spectrum, treatment practices, and outcome. I3 Aspergillus Study Group. Medicine (Baltimore) 2000;79:250-60.

97. Paradis IL, Williams P. Infection after lung transplantation. Sem Respir Infect 1993;8:207-15.

98. Mylonakis E, Barlam TF, Flanigan T, Rich JD. Pulmonary aspergillosis and invasive disease in AIDS: Review of 342 cases. Chest 1998;114:251-62.

99. Holding KJ, Dworkin MS, Wan PC, et al. Aspergillosis among people infected with human immunodeficiency virus: Incidence and survival. Adult and Adolescent Spectrum of HIV Disease Project. Clin Infect Dis 2000;31:1253-7.

100. Hines DW, Haber MH, Yaremko L, Britton C, McLawhon RW, Harris AA. Psuedomembranous tracheobronchitis caused by Aspergillus. Am Rev Respir Dis 1991;143:1408-11.

101. Ganassini A, Cazzadori A. Invasive pulmonary aspergillosis complicating bronchopulmonary aspergillosis. Respir Med 1995;89:143-5.

102. Apostolidis J, Tsandekidi M, Kousiafes D, et al. Short-course corticosteroid-induced pulmonary and apparent cerebral aspergillosis in a patient with idiopathic thrombocytopenic purpura. Blood 2001;98:2875-7.

103. Kemper CA, Hostetler JS, Follansbee SE, et al. Ulcerative and plaque-like tracheobronchitis due to infection with Aspergillus in patients with AIDS. Clin Infect Dis 1993;17:344-52.

104. Young RC, Bennett JE, Vogel CL, Carbone PP, DeVita VT. Aspergillosis. The spectrum of the disease of 98 patients. Medicine (Baltimore) 1970;49:147-73.

105. Kramer MR, Denning DW, Marshall SE, et al. Ulcerative tracheobronchitis after lung transplantation. A new form of invasive aspergillosis. Am Rev Respir Dis 1991;144:552-6.

106. Muquim A, Dial S, Menzies D. Invasive aspergillosis in patients with chronic obstructive pulmonary diseases. Can Respir J 2005;12:199-204.

107. Young RC, Vogel CL, DeVita VT. Aspergillus lobar pneumonia. JAMA 1969;208:1156-62.

108. Logan PM, Primack SL, Miller RR, Müller NL. Invasive aspergillosis of the airways: Radiographic, CT, and pathologic findings. Radiology 1994;193:383-8

109. Gefter WB. The spectrum of pulmonary aspergillosis. J Thorac Imaging 1992;7:56-74.

110. Horvath JA, Dummer S. The use of respiratory-tract cultures in the diagnosis of invasive pulmonary aspergillosis. Am J Med 1996;100:171-8.
111. Yu VL, Muder RR, Poorsattar A. Significance of isolation of Aspergillus from the respiratory tract in diagnosis of invasive aspergillosis. Results from a three-year prospective study. Am J Med 1986;81:249-54.

112. Levy H, Horak DA, Tegtmeier BR, Yokota SB, Forman SJ. The value of bronchoalveolar lavage and bronchial washings in the diagnosis of invasive pulmonary aspergillosis. Respir Med 1992;86:243-8

113. Kahn FW, Jones JM, England DM. The role of bronchoalveolar lavage in the diagnosis of invasive pulmonary aspergillosis. Am J Clin Pathol 1986;86:518-23.

114. Reichenberger F, Habicht J, Matt P, et al. Diagnostic yield of bronchoscopy in histologically proven invasive pulmonary aspergillosis. Bone Marrow Transplant 1999;24:1195-9.

115. Rogers TR, Haynes KA, Barnes RA. Value of antigen detection in predicting invasive pulmonary aspergillosis. Lancet 1990;336:1210-3.

116. Marr KA, Balajee SA, McLaughlin L, et al. Detection of galactomannan antigenemia by enzyme immunoassay for the diagnosis of invasive aspergillosis: Variables that affect performance. J Infect Dis 2004;190:641-9.

117. Haynes KA, Latge JP, Rogers TR. Detection of Aspergillus antigens associated with invasive infection. J Clin Microbiol 1990;28:2040-4.

118. Patterson TF, Miniter P, Patterson JE, Rappeport JM, Andriole VT. Aspergillus antigen detection in the diagnosis of invasive aspergillosis. J Infect Dis 1995;171:1553-8.

119. Maertens J, Van Eldere J, Verhaegen J, et al. Use of circulating galactomannan screening for early diagnosis of invasive aspergillosis in allogeneic stem cell transplant recipients. J Infect Dis 2002;186:1297-306.

120. Tomee JF, Mannes GP, Van Der Bij W, et al. Serodiagnosis and monitoring of Aspergillus infections after lung transplantation. Ann Intern Med 1996;125:197-201.

121. Hearn VM, Pinel C, Blachier S, Ambroise-Thomas P, Grillot R. Specific antibody detection in invasive aspergillosis by analytical isoelectrofocusing and immunoblotting methods. J Clin Microbiol 1995;33:982-6

122. Golbang N, Burnie JP, Matthews RC. A polymerase chain reaction enzyme immunoassay for diagnosing infection caused by Aspergillus fumigatus. J Clin Pathol 1999;52:419-23.

123. Kawamura S, Maesaki S, Noda T, et al. Comparison between PCR and detection of antigen in sera for diagnosis of pulmonary aspergillosis. J Clin Microbiol 1999;37:218-20.

124. Yamakami Y, Hashimoto A, Yamagata E, et al. Evaluation of PCR for detection of DNA specific for Aspergillus species in sera of patients with various forms of pulmonary aspergillosis. J Clin Microbiol 1998;36:361-23.

125. Denning DW, Stevens DA. Antifungal and surgical treatment of invasive aspergillosis: Review of 2121 published cases. Rev Infect Dis 1990;12:1147-201. (Erratum in 1991;13:345).

126. Burch PA, Karp JE, Merz WG, Kuhlman JE, Fishman EK. Favorable outcome of invasive aspergillosis in patients with acute leukemia. J Clin Oncol 1987;5:1985-93.

127. Denning DW. Therapeutic outcome in invasive aspergillosis. Clin Infect Dis 1996;23:608-15.

128. Walsh TJ, Hiemenz JW, Seibel NL, et al. Amphotericin B lipid complex for invasive fungal infections: Analysis of safety and efficacy in 556 cases. Clin Infect Dis 1998;26:1383-96.

129. White MH, Anaissie EJ, Kusne S, et al. Amphotericin B colloidal dispersion vs amphotericin B as therapy for invasive aspergillosis. Clin Infect Dis 1997;24:635-42.

130. Ng TT, Denning DW. Liposomal amphotericin B (AmBisome) therapy in invasive fungal infections. Evaluation of United Kingdom compassionate use data. Arch Intern Med 1995;155:1093-8.

131. Bowden RA, Cays M, Gooley T, Mamelok RD, van Burik JA. Phase I study of amphotericin B colloidal dispersion for the treatment of invasive fungal infections after marrow transplant. J Infect Dis 1996;173:1208-15.

132. Oppenheim BA, Herbrecht R, Kusne S. The safety and efficacy of amphotericin B colloidal dispersion in the treatment of invasive mycoses. Clin Infect Dis 1995;21:1145-53.

133. Mills W, Chopra R, Linch DC, Goldstone AH. Liposomal amphotericin B in the treatment of fungal infections in neutropenic patients: A single-centre experience of 133 episodes in 116 patients. Br J Haematol 1994;86:754-60.

134. Ringden O, Meunier F, Tollemar J, et al. Efficacy of amphotericin B encapsulated in liposomes (AmBisome) in the treatment of 
invasive fungal infections in immunocompromised patients. J Antimicrob Chemother 1991;28(Suppl B):73-82.

135. Stevens DA, Lee JY. Analysis of compassionate use itraconazole therapy for invasive aspergillosis by the NIAID Mycoses Study Group criteria. Arch Intern Med 1997;157:1857-62.

136. Denning DW, Lee JY, Hostetler JS, et al. NIAID Mycoses Study Group multicenter trial of oral itraconazole therapy for invasive aspergillosis. Am J Med 1994;97:135-44. (Erratum in 1994;97:497).

137. Van't Wout JW. Itraconazole in neutropenic patients. Chemotherapy 1992;38(Suppl 1):23-6.

138. Herbrecht R, Denning DW, Patterson TF, et al; Invasive Fungal Infections Group of the European Organisation for Research and Treatment of Cancer and the Global Aspergillus Study Group. Voriconazole versus amphotericin B for primary therapy of invasive aspergillosis. N Engl J Med 2002;347:408-15.

139. Imhof A, Balajee SA, Fredricks DN, et al. Breakthrough fungal infections in stem cell transplant recipients receiving voriconazole. Clin Infect Dis 2004;39:743-6.

140. Wiederhold NP, Kontoyiannis DP, Chi J, et al. Pharmacodynamics of caspofungin in a murine model of invasive aspergillosis: Evidence of concentration-dependent activity. J Infect Dis 2004;190:1464-71.

141. Ota S, Tanaka J, Kahata K, et al. Successful micafungin (FK463) treatment of invasive aspergillosis in a patient with acute lymphoblastic leukemia in a phase II study. Int J Hematol 2004;79:390-3.

142. Yokote T, Akioka T, Oka S, et al. Successful treatment with micafungin of invasive aspergillosis in acute myeloid leukemia, with renal failure due to amphotericin B therapy. Ann Hematol 2004;83:64-6.

143. Caillot D, Casasnovas O, Bernard A, et al. Improved management of invasive pulmonary aspergillosis in neutropenic patients using early thoracic computed tomographic scan and surgery. J Clin Oncol 1997;15:139-47.

144. Pidhorecky I, Urschel J, Anderson T. Resection of invasive pulmonary aspergillosis in immunocompromised patients. Ann Surg Oncol 2000; 7:312-7.

145. Bernhisel-Broadbent J, Camargo EE, Jaffe HS, Lederman HM. Recombinant human interferon-gamma as adjunct therapy for Aspergillus infection in patients with chronic granulomatous disease. J Infect Dis 1991;163:908-11.

146. Pui CH, Boyett JM, Hughes WT, et al. Human granulocyte colony-stimulating factor after induction chemotherapy in children with acute lymphoblastic leukemia. N Engl J Med 1997;336:1781-7.

147. Nemunaitis J. Use of macrophage colony-stimulating factor in the treatment of fungal infections. Clin Infect Dis 1998;26:1279-81.
148. Bhatia S, McCullough J, Perry EH, Clay M, Ramsay NK, Neglia JP. Granulocyte transfusions: Efficacy in treating fungal infections in neutropenic patients following bone marrow transplantation. Transfusion 1994;34:226-32.

149. Beyer J, Schwartz S, Heinemann V, Siegert W. Strategies in prevention of invasive pulmonary aspergillosis in immunosupressed or neutropenic patients. Antimicrob Agents Chemother 1994;38:911-7

150. Beyer J, Shwartz S, Barzen G, et al. Use of Amphotericin B aerosols for the prevention of pulmonary aspergillosis. Infection 1994;22:143-8.

151. Harousseau JL, Dekker AW, Stamatoullas-Bastard A, et al. Itraconazole oral solution for primary prophylaxis of funga infections in patients with hematological malignancy and profound neutropenia: A randomized, double blind, double placebo, multicenter trial comparing itraconazole and amphotericin B. Antimicrob Agents Chemother 2000;44:1887-93.

152. Lamy T, Bernard M, Courtois A, et al. Prophylactic use of itraconazole for the prevention of invasive pulmonary aspergillosis in high risk neutropenic patients. Leuk Lymphoma 1998;30:163-74.

153. Hamacher J, Spiliopoulos A, Kurt AM, Nicod LP. Pre-emptive therapy with azoles in lung transplant patients. Geneva Lung Transplantation Group. Eur Respir J 1999;13:180-6.

154. Binder RE, Faling LJ, Pugatch RD, Mahasaen C, Snider GL. Chronic necrotizing pulmonary aspergillosis: A discrete clinical entity. Medicine (Baltimore) 1982;61:109-24.

155. Saraceno JL, Phelps DT, Ferro TJ, Futerfas R, Schwartz DB. Chronic necrotizing pulmonary aspergillosis: Approach to management. Chest 1997;112:541-8.

156. Franquet T, Muller NL, Gimenez A, Domingo P, Plaza V, Bordes R. Semiinvasive pulmonary aspergillosis in chronic obstructive pulmonary disease: Radiologic and pathologic findings in nine patients. AJR Am J Roentgenol 2000;174:51-6.

157. Hillerdal G. Pulmonary aspergillus infection invading the pleura. Thorax 1981;36:745-51.

158. Krakowka P, Rowinska E, Halweg H. Infection of the pleura by Aspergillus fumigatus. Thorax 1970;25:245-53

159. Denning DW, Riniotis K, Dobrashian R, Sambatakou H. Chronic cavitary and fibrosing pulmonary and pleural aspergillosis: Case series, proposed nomenclature change, and review. Clin Infect Dis 2003;37(Suppl 3):S265-80.

160. Walsh TJ, Bulkley BH. Aspergillus pericarditis: Clinical and pathological features in the immunocompromised patient. Cancer 1982;49:48-54. 


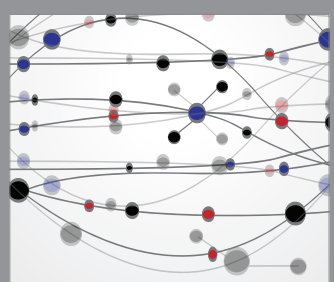

The Scientific World Journal
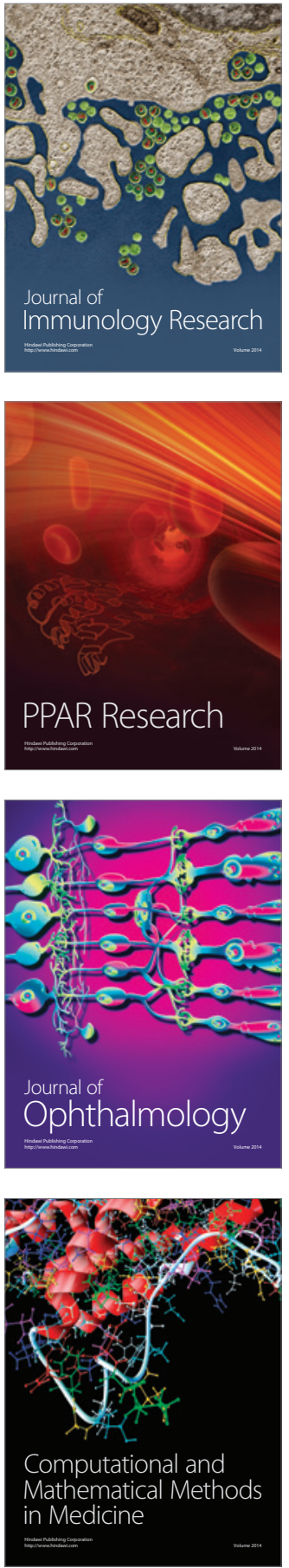

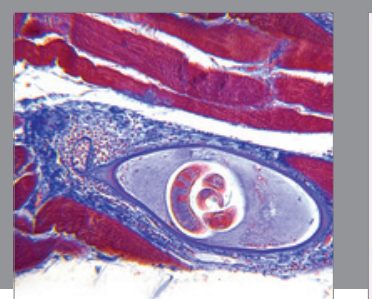

Gastroenterology Research and Practice

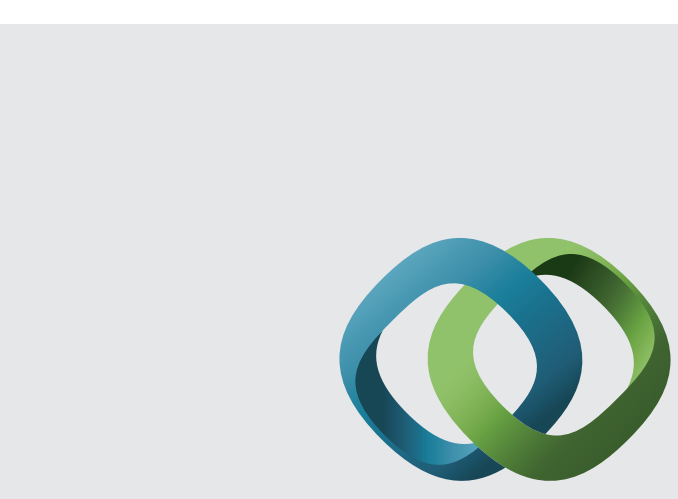

\section{Hindawi}

Submit your manuscripts at

http://www.hindawi.com
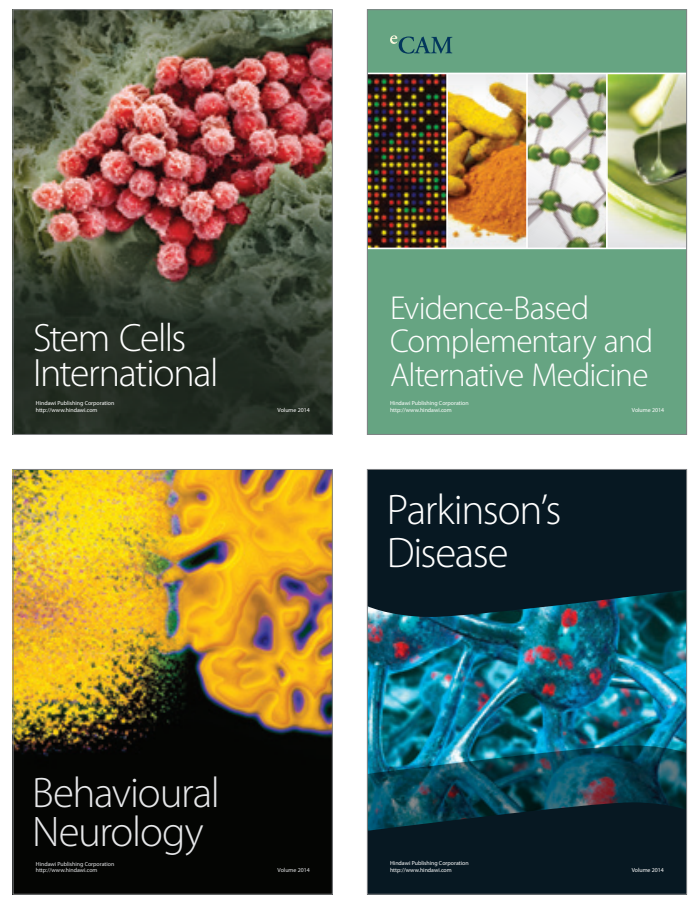
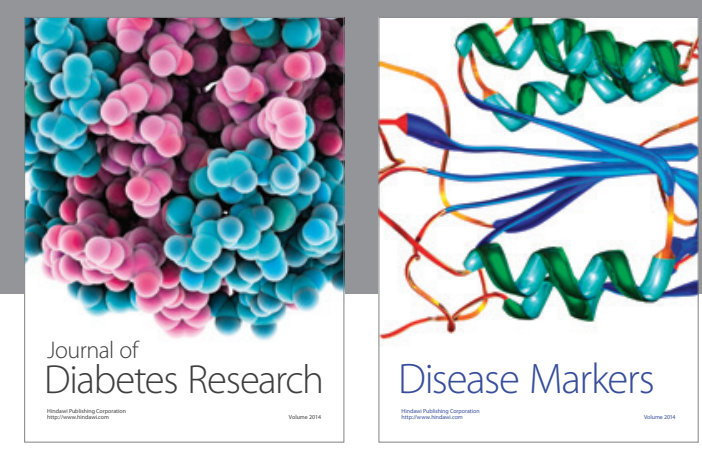

Disease Markers
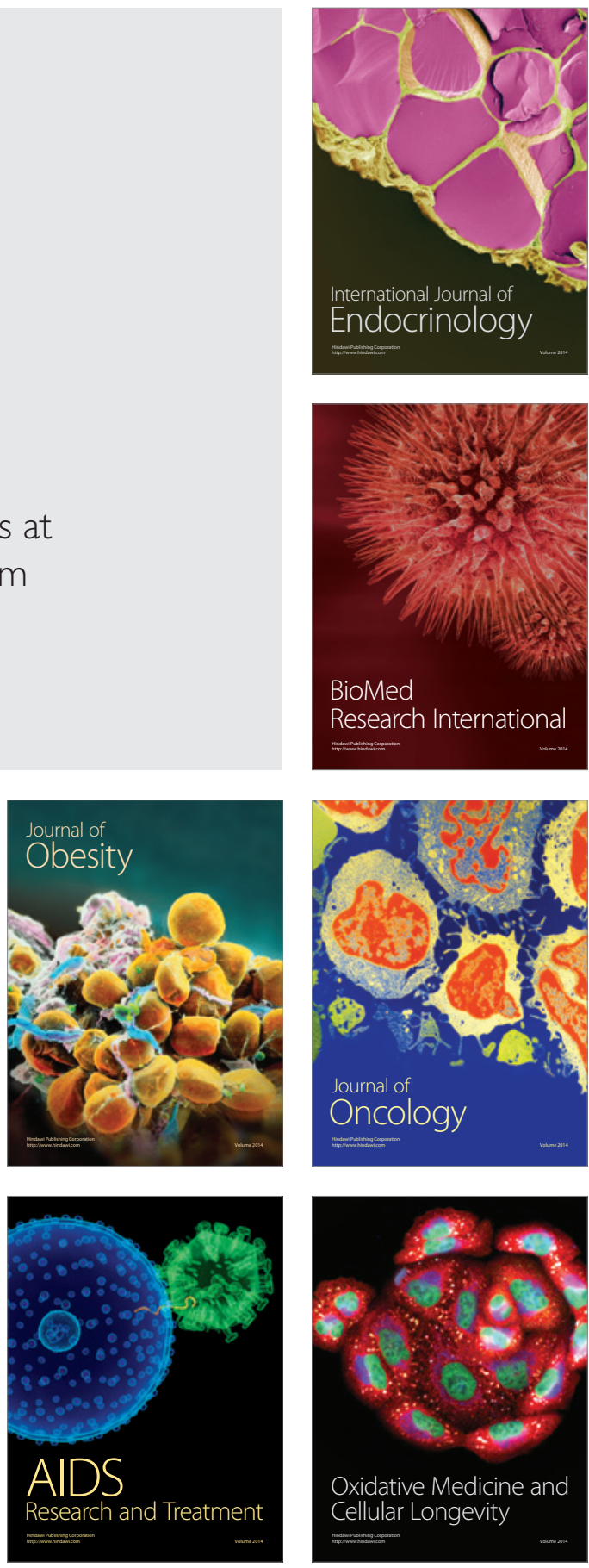